\title{
The accuracy of interpretation of emergency abdominal CT in adult patients who present with non-traumatic abdominal pain: results of a UK national audit
}

\author{
D.C. Howlett ${ }^{\mathrm{a}}$, K. Drinkwater ${ }^{\mathrm{b}, *}$, C. Frost $^{\mathrm{c}}$, A. Higginson ${ }^{\mathrm{d}}$, C. Ball ${ }^{\mathrm{d}}$, \\ G. Maskell ${ }^{\mathrm{e}}$ \\ ${ }^{\text {a }}$ Department of Radiology, Eastbourne Hospital, Eastbourne, UK \\ ${ }^{\mathrm{b}}$ Department of Professional Practice, The Royal College of Radiologists, London, UK \\ ${ }^{\mathrm{c}}$ Department of Medical Statistics, London School of Hygiene and Tropical Medicine, London, UK \\ ${ }^{\mathrm{d}}$ Department of Radiology, Queen Alexandra Hospital, Portsmouth, UK \\ e Department of Radiology, Royal Cornwall Hospital, Truro, UK
}

\section{ARTICLE INFORMATION}

\section{Article history:}

Received 18 July 2016

Received in revised form

14 October 2016

Accepted 17 October 2016
AIM: To evaluate major/minor discrepancy rates for provisional (initial) and addendum (supplementary senior review) emergency computed tomography (CT) reports in patients presenting with non-traumatic abdominal pain.

MATERIALS AND METHODS: Ethical approval for this type of study is not required in the UK. All radiology departments with an approved lead for audit registered with the Royal College of Radiologists were invited to participate in this retrospective audit. The first 50 consecutive patients (25 surgical, 25 non-surgical) who underwent emergency abdominal CT for nontraumatic abdominal pain in 2013 were included. Statistical analyses were performed to identify organisational and report/patient-related variables that might be associated with major discrepancy.

RESULTS: One hundred and nine (58\%) of 188 departments supplied data to the study with a total of 4,931 patients (2,568 surgical, 2,363 non-surgical). The audit standard for provisional report major discrepancy was achieved for registrars (target $<10 \%$, achieved $4.6 \%$ ), for on-site consultants (target $<5 \%$, achieved $3.1 \%$ ) and consultant addendum (target $<5 \%$, achieved $2.9 \%$ ). Off-site reporters failed to meet the standard target ( $<5 \%$, achieved $8.7 \%$ overall and $12.7 \%$ in surgical patients). The standard for patients coming to harm was not met in the surgical group (target $<1 \%$, achieved $1.5 \%$ ) and was narrowly missed overall (target $<1 \%$, achieved $1 \%$ ).

CONCLUSION: This study should be used to provide impetus to improve aspects of out-ofhours CT reporting. Clear benefits of CT interpretation/review by on-site and more senior (consultant) radiologists have been demonstrated.

(c) 2016 The Royal College of Radiologists. Published by Elsevier Ltd. All rights reserved.

\footnotetext{
* Guarantor and correspondent: K. Drinkwater, Department of Professional Practice, The Royal College of Radiologists, 63 Lincoln's Inn Fields, London WC2A 3JW, UK. Tel.: +44 (0)20 74051282.

E-mail address: karl_drinkwater@rcr.ac.uk (K. Drinkwater).
} 


\section{Introduction}

Acute abdominal pain, out of the trauma setting, is a common presenting symptom in the emergency department, with a wide spectrum of underlying causes. ${ }^{1}$ Abdominopelvic computed tomography (CT) has assumed an increasingly important role in the evaluation and diagnosis of these patients and is widely used as an integral part of surgical triage. ${ }^{2-4}$ Abdominopelvic CT, although highly accurate in the assessment of the acute abdomen, can be challenging to report particularly in patients who are acutely unwell. The rapid increase in utilisation of CT, particularly out of hours, has created reporting pressures within UK radiology departments and this has led to the development of different reporting models. Provisional (initial) CT reports may be issued by trainee radiologists (registrars) with subsequent review by senior on-site consultant radiologists, or reports may be issued by consultants themselves. Alternatively in many departments reporting may be carried out by radiologists working off-site with no affiliation to the department where the imaging occurs. Off-site reporters are typically of consultant level or equivalent, but may not be trained or working within the UK. Off-site reporting is particularly utilised out of hours, a practice that is well recognised across Europe and North America. Both registrar and off-site reports may be supplemented by an addendum report provided later by an on-site consultant. Alongside these changes in practice has been recognition of the concept of radiological "error", more often referred to as "discrepancy" and the relationship of a discrepant report to potential or actual harm to the patient. ${ }^{5,6}$

Emergency abdominal or abdominopelvic CT performed out of hours in acutely ill patients is a complex investigation with the potential to impact positively or negatively on patient outcomes depending on the accuracy and timeliness of the report. Current UK reporting models involve radiologists of varying expertise and experience, some of whom are offsite and remote to both the patient and clinical interaction.

The aims of this national, UK-wide audit on acute nontraumatic abdominopelvic CT reporting in surgical and non-surgical groups include assessment of major/minor discrepancy rates for provisional (initial) and also addendum (supplementary) reports in unselected patients across a wide range of institutions; to examine factors affecting major discrepancy rate at the level of the provisional report; to examine reporting factors affecting cases of major discrepancy where patients came to harm and also to assess the nature of the harm; to obtain sensitivity and specificity of $\mathrm{CT}$ in the more common pathologies in both surgical and non-surgical patient groups; to document any added value of a consultant addendum report and to evaluate the availability of provisional and addendum reports preoperatively in the surgical group.

\section{Materials and methods}

The Royal College of Radiologists (RCR) works closely with individual radiology departments across the four countries within the UK, nominated individuals/fellows within the departments are responsible for co-ordinating both local audits and national RCR audit projects. As part of this emergency CT abdominal reporting audit, all departmental audit leads were contacted by email and invited to participate and submit audit data to the RCR on behalf of their departments. Formal ethical approval for this type of study is not required in the UK as all submitted data are anonymised and only used to promote best medical practice.

Departments were requested to submit patient data in both non-surgical and surgical cohorts. Those departments with no on-site general surgery only submitted data for the non-surgical group. Access to relevant patient data on PACS (picture archiving and communication system), RIS (radiology information system), and the patient record was necessary for inclusion.

\section{Non-surgical group}

A retrospective search was undertaken to identify 25 consecutive non-traumatic adult ( $>16$ years) emergency patients who underwent abdominopelvic CT from 1 January 2013 onwards from the radiological department database. The patients all had out-of -hours ( $6 \mathrm{pm}-8$ am weekdays or anytime at the weekend) emergency abdominal or abdominopelvic CT but no subsequent laparotomy. Patients who had another intervention during this admission, e.g., colonic/double-J stent, percutaneous drainage, laparoscopy (to include laparoscopic surgical interventions) were included in this category. Patients who underwent noncontrast CT for suspected renal calculus were excluded from the audit.

\section{Surgical group}

Retrospective identification from 1 January 2013 onwards of 25 consecutive non-traumatic adult patients who had out-of-hours abdominal/abdominopelvic CT and had subsequent laparotomy. For the purposes of the audit, it was expected that for the majority of patients $\mathrm{CT}$ would have been performed within 24-48 hours pre-laparotomy; however, patients could still be included if the time interval was $<48$ hours but the CT deemed pertinent to that episode of care.

\section{Data collection}

Data were entered into the Microsoft Office Excel 2007 spreadsheets: "institutional", "non-surgical", and "surgical" group questionnaires. Auditors were able to toggle between the three questionnaires and also to access a drop-down glossary of expanded terms (diagnoses) for truncated items in the drop-down lists. These three questionnaires would provide a range of contextual data, which would then be used to explore potential relationships to the chosen audit standards. Details of the three questionnaires are included in Electronic Supplementary Material Appendix A.

The institutional questionnaire was used to assess more generic aspects relating to $\mathrm{CT}$ reporting out of hours, including the use of radiology trainees/registrars and off- 
site reporters in the provision of on call reports as well as on-site hospital-based consultants. The institutional questionnaire also explored availability of more specialised gastrointestinal (GI) radiology on-site, either as primary or supplementary/addendum reporter. A GI interest was classified as a radiologist with formal GI reporting sessions and involvement in GI multidisciplinary team meetings (MDT); GI subspecialty interest was defined as a minimum of five sessions of GI reporting per week.

The "non-surgical" and "surgical" questionnaires looked more specifically at the patient journey, examining the diagnosis of the provisional report, nature of provisional (initial) reporter, presence/absence of an addendum report and its concordance with the provisional report. Correlation of the provisional report with the laparotomy findings was assessed in the surgical group together with the presence/ absence of a preoperative provisional and/or addendum report either documented in the patient notes or validated on the RIS system.

For any given case the questionnaires only allowed the auditor to select a single and representative major/minor diagnosis. The presence of additional secondary diagnoses could be selected but not itemised.

Auditors were instructed to select the provisional and/or addendum report diagnosis, recording their own auditor diagnosis if non-concordant and then also to record the laparotomy diagnosis. This process would allow recording of major/minor discrepancy between reports by the auditor, also the type of discrepancy and using patient/radiology records to assess any harm that may have come to the patient. Correlation with surgical findings would also be undertaken.

Drop-down lists were widely used to facilitate data entry, data validation, and configuration of restricted data entry to valid responses. Cell references in formulae enabled summary responses to be displayed and updated automatically. The questionnaires were initially piloted amongst members of the RCR audit committee to evaluate content and to confirm ease of use. The identity of respondents in terms of (1) teaching or district general hospital and (2) region of the UK was used to evaluate potential bias between respondents and non-respondents. Responses were incomplete in some parts of the questionnaires, with such data recorded as "no response".

\section{The CT auditor}

For the purposes of the audit, it was proposed that the auditor evaluating provisional and addendum reports and the CT findings would be a substantive consultant working on-site in the auditing institution. This individual should have experience in reporting abdominal CT. In cases of potential major discrepancy, it was recommended that there should be case review with another on-site consultant colleague, preferably with an interest in GI/abdominal radiology and a consensus reached.

It was specified within the audit proforma that the CT auditor should review the CT images blinded to original report content/reporter identity with or without surgical findings and then review the CT reports (provisional with or without an addendum) and record concordance/discrepancy and their own diagnosis in cases of discrepancy. The CT auditor would then review the patient notes/RIS in surgical patients to determine the presence/timing of a record of the provisional/addendum report and would also review provisional/addendum report findings compared to laparotomy findings in surgical patients.

\section{Discrepancies}

A major discrepancy comprised a change, or potential change in diagnosis or treatment as a result of either addendum report or CT auditor review. A minor discrepancy occurred where there were minor issues in provisional/ addendum reports unlikely to result in harm or change in management. Major discrepancies were coded as false positive (provisional report diagnosis positive findings, negative on auditor review); false negative (provisional report negative diagnosis, positive findings on auditor review); misdiagnosis (incorrect provisional diagnosis); or indeterminate report (an indeterminate report defined as an inappropriately wide range of differential diagnoses, containing the correct diagnosis[es] but with no attempt at triaging the diagnoses or guiding the clinician to the most likely explanation for CT findings).

A dropdown menu also allowed grading of each case into (1) major discrepancy patient came to harm (harm might include death, unnecessary intervention (e.g. colonoscopy, endoscopy, drainage), delay in diagnosis or treatment; (2) major discrepancy patient did not come to harm; (3) major discrepancy, outcome uncertain; (4) minor discrepancy; (5) concordance with reports, no issues of concern.

\section{Audit standards}

The derivation of audit standards followed similar practice previously outlined for RCR national audits. ${ }^{7}$ It is established practice within the RCR to review all available literature and to adopt a standard/set of standards that is considered by the RCR audit committee to be both practical and achievable in everyday clinical practice.

The selected audit standards are included in Table 1 (compliance with standards is also documented in this table). The standards were derived following careful evaluation of relevant, current published literature taking into account the differing clinical scenarios and definitions of discrepancy included in these publications. ${ }^{8-20}$ A comparison of the national audit findings against these standards were expressed as counts and percentages. A search of all available published literature (from 1950 onwards) was undertaken using the MEDLINE and National Health Service evidence (including the Cochrane library of systematic reviews and the National library of guidelines) to establish supporting literature and confirm/derive figures for the audit standards and made available during audit committee deliberations.

For the purposes of the audit, there were three main groups providing provisional (initial) CT reports (1) 
Table 1

Compliance with audit standards.

\begin{tabular}{|c|c|c|c|c|c|c|c|c|c|c|}
\hline \multirow[t]{2}{*}{ Recommendation } & \multirow[t]{2}{*}{ Target } & \multicolumn{3}{|c|}{ Non-surgical } & \multicolumn{3}{|c|}{ Surgical } & \multicolumn{3}{|l|}{ ALL } \\
\hline & & $\%$ & $95 \% \mathrm{Cl}^{\mathrm{a}}$ & $n / N$ & $\%$ & $95 \% \mathrm{CI}$ & $n / N$ & $\%$ & $95 \% \mathrm{CI}$ & $n / N$ \\
\hline $\begin{array}{l}\text { Major discrepancy rate (provisional } \\
\text { report - registrar) }{ }^{b}\end{array}$ & $<10 \%$ & 2.8 & $(1.8 \%, 4.1 \%)$ & $25 / 887$ & 6.3 & $(4.3 \%, 9.2 \%)$ & $56 / 882$ & 4.6 & $(3.4 \%, 6.1 \%)$ & $81 / 1769$ \\
\hline $\begin{array}{l}\text { Major discrepancy rate (provisional } \\
\text { report - off-siter) }\end{array}$ & $<5 \%$ & 5.2 & $(2.4 \%, 9.9 \%)$ & $11 / 210$ & 12.7 & $(8.1 \%, 19.3 \%)$ & $23 / 181$ & 8.7 & $(6 \%, 13.1 \%)$ & $34 / 391$ \\
\hline $\begin{array}{l}\text { Major discrepancy rate (provisional } \\
\text { report - trust consultant radiologist) }\end{array}$ & $<5 \%$ & 2.4 & $(1.6 \%, 3.6 \%)$ & $36 / 1471$ & 3.9 & $(2.7 \%, 5.6 \%)$ & $49 / 1263$ & 3.1 & $(2.3 \%, 4.3 \%)$ & $85 / 2734$ \\
\hline $\begin{array}{l}\text { Major discrepancy rate (addendum } \\
\text { report) }\end{array}$ & $<5 \%$ & 3.1 & $(1.9 \%, 4.5 \%)$ & $19 / 621$ & 2.7 & $(1.6 \%, 4.1 \%)$ & $17 / 635$ & 2.9 & $(2.1 \%, 3.8 \%)$ & $36 / 1256$ \\
\hline $\begin{array}{l}\text { Overall major discrepancy rate where } \\
\text { the patient came to harm }\end{array}$ & $<1 \%$ & 0.6 & $(0.3 \%, 1 \%)$ & $15 / 2568$ & 1.5 & $(1 \%, 2.4 \%)$ & $36 / 2363$ & 1.0 & $(0.7 \%, 1.5 \%)$ & $51 / 4931$ \\
\hline $\begin{array}{l}\text { Minor discrepancy rate (provisional } \\
\text { report - registrar) }\end{array}$ & $<20 \%$ & 10.7 & $(8.4 \%, 13.4 \%)$ & $95 / 887$ & 6.1 & $(4.2 \%, 8.7 \%)$ & $54 / 882$ & 8.4 & $(6.9 \%, 10.1 \%)$ & $149 / 1769$ \\
\hline $\begin{array}{l}\text { Minor discrepancy rate (provisional } \\
\text { report - off-siter) }\end{array}$ & $<10 \%$ & 11.4 & $(6.8 \%, 19.4 \%)$ & $24 / 210$ & 9.9 & $(5.2 \%, 16.9 \%)$ & $18 / 181$ & 10.7 & $(7 \%, 16.8 \%)$ & $42 / 391$ \\
\hline $\begin{array}{l}\text { Minor discrepancy rate (provisional } \\
\text { report - trust consultant radiologist) }\end{array}$ & $<10 \%$ & 6.6 & $(4.9 \%, 8.7 \%)$ & $97 / 1471$ & 5.8 & $(4.3 \%, 7.8 \%)$ & $73 / 1263$ & 6.2 & $(5 \%, 7.7 \%)$ & $170 / 2734$ \\
\hline $\begin{array}{l}\text { Minor discrepancy rate (addendum } \\
\text { report) }\end{array}$ & $<10 \%$ & 8.9 & $(6.5 \%, 11.6 \%)$ & $55 / 621$ & 5.7 & $(3.9 \%, 8.9 \%)$ & $36 / 635$ & 7.2 & $(5.5 \%, 9.4 \%)$ & $91 / 1256$ \\
\hline $\begin{array}{l}\text { Correlation CT report with laparotomy } \\
\text { findings (provisional report - } \\
\text { registrar) }\end{array}$ & $>80 \%$ & - & & - & 83.7 & $(79.8 \%, 86.6 \%)$ & $728 / 870$ & - & & \\
\hline $\begin{array}{l}\text { Correlation CT report with laparotomy } \\
\text { findings (provisional report - off- } \\
\text { siter) }\end{array}$ & $>90 \%$ & - & & - & 78.9 & $(72 \%, 84.3 \%)$ & $138 / 175$ & - & & \\
\hline $\begin{array}{l}\text { Correlation CT report with laparotomy } \\
\text { findings (provisional report, on-site } \\
\text { trust consultant) }\end{array}$ & $>90 \%$ & - & & - & 88.9 & $(87 \%, 90.5 \%)$ & $1094 / 1231$ & - & & \\
\hline $\begin{array}{l}\text { Correlation CT report with laparotomy } \\
\text { findings (addendum report) }\end{array}$ & $>90 \%$ & - & & - & 87.2 & $\left(83.5 \%, 90.0 \%^{\mathrm{e}}\right)$ & $554 / 635$ & - & & \\
\hline $\begin{array}{l}\text { Written or validated report available } \\
\text { prior to surgery (provisional report) }\end{array}$ & $100 \%$ & - & & - & 98.3 & $(96.9 \%, 99.2 \%)$ & $2197 / 2234$ & - & & \\
\hline $\begin{array}{l}\text { Written or validated report available } \\
\text { prior to surgery (addendum report) }\end{array}$ & $100 \%$ & - & & - & 64.3 & $(53.9 \%, 73.7 \%)$ & $356 / 554$ & - & & \\
\hline
\end{tabular}

a If the whole of a 95\% confidence interval (CI) lies on the correct side of a target value then we can say that we have statistically significant evidence that the

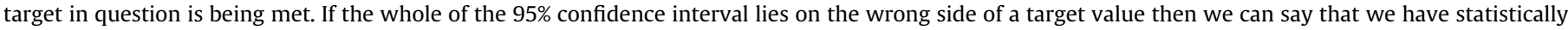

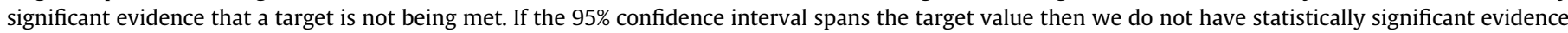
either way.

b A registrar is a trainee radiologist (provides provisional/initial computed tomography [CT] reports).

c An off-siter is a radiologist, usually senior (consultant level) working for an outsourcing agency and remote from the scanning hospital (provides provisional/initial CT reports).

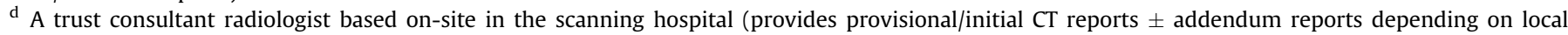
policies).

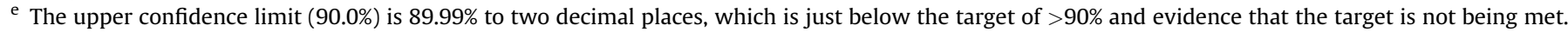

registrar (trainee radiologist); (2) off-siter (radiologist working remotely for an outsourcing agency at consultant level or equivalent); and (3) consultant radiologist on-site (may or may not have GI radiology expertise). Addendum (supplementary) reports to initial, provisional reports were provided by hospital-based on-site consultant radiologists with varying degrees of GI radiology expertise.

\section{Statistical analysis}

Exploratory analyses of all variables in the three questionnaires (institutional, non-surgical, and surgical) were performed to identify any significant variables that might predict discrepancy of the provisional report with the auditor review. The auditor was used as the reference standard. The variables investigated included: nature of provisional reporter (registrar, on-site consultant or off- siter); effect of registrar discussion of case with on-site consultant (if documented); effect of type of on-site consultant (general versus GI radiologist) and also presence/absence of GI radiologist on-site; effect of district general hospital versus teaching hospital; effect of availability of on-call registrar reporting of CT (present/absent); effect of availability of on-call CT reporting by on site consultants; effect of availability of on-call reporting of CT by off-site radiologists.

For each of these variables, major discrepancy risk ratios $(95 \% \mathrm{CI})$ were estimated from generalised linear models with a binary outcome and log link, with robust standard errors to allow for non-independence of results from the same hospital. Separate models were first fitted to the surgical and non-surgical group data. A model was then fitted to the combined data: this allowed risks to differ in the surgical and non-surgical groups, as well as according to the variable 
being investigated. The model was also extended to allow for interactions (i.e., allowing the discrepancy rate ratios to differ between the surgical and non-surgical groups). For institutional comparisons (i.e., district general hospitals versus teaching hospital) further models were fitted adjusting for differences in the proportions of registrar, consultant, and off-site reports by including appropriate indicator variables as covariates in the models. An analogous series of models was used to analyse risk ratios for any discrepancy (major and minor combined).

For those subjects where an addendum report was available, conditional logistic regression modes (with robust standard errors that allowed for non-independence of results from the same hospital) were used to investigate the value of the addendum report. The paired outcomes compared by the model were (1) whether or not there was a major discrepancy between the provisional report and the auditor, and (2) whether or not there was a major discrepancy between the addendum report and the auditor. Analogous analyses were performed for any discrepancy (major and minor combined). Sensitivity and specificity calculations were undertaken in relation to the ten most commonly occurring diagnosed pathologies in both the surgical and non-surgical groups. To allow for nonindependence of results from the same hospital in Table 1 (compliance with standards) 95\% confidence intervals for percentages were computed using the bootstrap: specifically, non-parametric, bias corrected and accelerated 95\% confidence intervals were calculated from 100,000 bootstrap samples clustered by hospital.

\section{Results}

The complete responses to the three audit questionnaires together are included in Electronic Supplementary Material Appendix A. A total of 109/188 eligible departments responded to the audit (58\%). Summary results of the institutional questionnaire/departmental demographics are included in Table 2. Case demographics are included in Table 3 (note that 4,931 patients were included in the audit: 2568 non-surgical group, 2363 surgical group; $48 \%$ male, $52 \%$ female). Table 3 also includes information on the source of the $\mathrm{CT}$ request and the location and seniority of the provisional reporters.

In $179 / 887$ (20.2\%) provisional registrar reports, there was evidence of discussion with an on-site consultant radiologist documented in the provisional report. Ninetyfive departments submitted 25 cases in the non-surgical group, the remainder submitted 24 . In the surgical group, one department submitted 26 cases, 78 departments submitted 25 cases and the remainder between 4 and 24 .

The identity of responding departments and hospitals were reviewed. The percentage of departments participating from teaching hospitals in England differed from district general hospitals by $<1 \%$. The geographic distribution of departments differed by $10.8 \%$ when respondents were compared with non-respondents in England. In Northern Ireland, the difference was 3.5\%, in Wales $1.3 \%$ and
Table 2

Department demographics (institutional questionnaire).

\begin{tabular}{|c|c|c|}
\hline & $n$ & $\%$ \\
\hline \multicolumn{3}{|l|}{ Home nation $(n=109)$} \\
\hline England & 89 & 81.7 \\
\hline Northern Ireland & 3 & 2.8 \\
\hline Scotland & 10 & 9.2 \\
\hline Wales & 7 & 6.4 \\
\hline \multicolumn{3}{|l|}{ CT auditor (primary reviewer) $(n=109)$} \\
\hline $\begin{array}{l}\text { Subspeciality interest GI radiology (min } 5 \text { sessions } \\
\text { per week) }\end{array}$ & 19 & 17.4 \\
\hline General radiologist & 55 & 50.5 \\
\hline General with GI interest (attends GI MDT) ${ }^{\mathrm{b}}$ & 26 & 23.9 \\
\hline Member BSGAR ${ }^{\mathrm{C}}$ & 9 & 8.3 \\
\hline \multicolumn{3}{|l|}{ 2nd CT auditor (consensus discrepancy opinion) ( $n=109$ ) } \\
\hline Subspeciality interest GI radiology & 23 & 21.1 \\
\hline General radiologist & 34 & 31.2 \\
\hline General with GI interest & 41 & 37.6 \\
\hline Member BSGAR & 8 & 7.3 \\
\hline Not applicable & 2 & 1.8 \\
\hline No response & 1 & 0.9 \\
\hline \multicolumn{3}{|l|}{ Type of institution ( $n=109)$} \\
\hline DGH (district general hospital) & 77 & 70.6 \\
\hline Teaching & 32 & 29.4 \\
\hline \multicolumn{3}{|l|}{ On-call CT reporting provided by registrar? $(n=109)$} \\
\hline Yes & 61 & 56.0 \\
\hline No & 48 & 44.0 \\
\hline \multicolumn{3}{|c|}{ On-call CT reporting provided by on-site trust consultant? ( $n=109)$} \\
\hline Yes & 64 & 58.7 \\
\hline Partial & 35 & 32.1 \\
\hline No & 10 & 9.2 \\
\hline \multicolumn{3}{|c|}{$\begin{array}{l}\text { On-call CT reporting provided by off-site radiologist? (outsourced) } \\
\quad(n=109)\end{array}$} \\
\hline Yes & 38 & 34.9 \\
\hline No & 71 & 65.1 \\
\hline \multicolumn{3}{|l|}{ On-call CT reports provided by: $(n=109)$} \\
\hline Transcription & 26 & 23.9 \\
\hline Voice recognition & 66 & 60.6 \\
\hline Other & 16 & 14.7 \\
\hline No response & 1 & 0.9 \\
\hline \multicolumn{3}{|l|}{ Speciality GI radiologist on-site $(n=109)$} \\
\hline Yes & 58 & 53.2 \\
\hline No & 51 & 46.8 \\
\hline \multicolumn{3}{|l|}{ Review of registrar on-call CT ( $n=61)$} \\
\hline Next morning & 35 & 57.4 \\
\hline Next working day & 13 & 21.3 \\
\hline Other & 2 & 3.3 \\
\hline No response & 11 & 18.0 \\
\hline \multicolumn{3}{|c|}{$\begin{array}{l}\text { Is there on-site review routinely of outsourced (non-trust) CT on-cal } \\
\text { reports? }(n=38)\end{array}$} \\
\hline Yes & 16 & 42.1 \\
\hline No & 22 & 57.9 \\
\hline \multicolumn{3}{|l|}{ Who reviews outsourced CT reports? $(n=16)$} \\
\hline Formal subspeciality interest GI radiology & 2 & 12.5 \\
\hline General radiologist & 11 & 68.8 \\
\hline General with GI interest & 2 & 12.5 \\
\hline No response & 1 & 6.3 \\
\hline \multicolumn{3}{|l|}{ Acute surgery on-site? $(n=109)$} \\
\hline Yes & 108 & 99.1 \\
\hline No & 1 & 0.9 \\
\hline
\end{tabular}

CT, computed tomography; GI, gastrointestinal; MDT, multidisciplinary team.

a Subspeciality interest GI radiology is a radiologist with a minimum of five sessions of GI radiology.

b General radiologist with GI interest is a radiologist with sessions in GI radiology and who attends GI multidisciplinary team meetings.

c BSGAR is the British Society of Gastrointestinal and Abdominal Radiology. 
Table 3

Case demographics.

\begin{tabular}{|c|c|c|c|c|}
\hline & \multirow{2}{*}{$\begin{array}{l}\begin{array}{l}\text { Non-surgical } \\
(n=2568)\end{array} \\
n\end{array}$} & \multirow[b]{2}{*}{$\%$} & \multirow{2}{*}{$\begin{array}{l}\begin{array}{l}\text { Surgical } \\
(n=2363)\end{array} \\
N\end{array}$} & \multirow[b]{2}{*}{$\%$} \\
\hline & & & & \\
\hline \multicolumn{5}{|l|}{ Home Nation } \\
\hline England & 2084 & 81.2 & 2013 & 85.2 \\
\hline Northern Ireland & 75 & 2.9 & 54 & 2.3 \\
\hline Scotland & 242 & 9.4 & 148 & 6.3 \\
\hline Wales & 167 & 6.5 & 148 & 6.3 \\
\hline \multicolumn{5}{|l|}{ Age } \\
\hline $16-20$ & 29 & 1.1 & 37 & 1.6 \\
\hline $21-30$ & 180 & 7.0 & 119 & 5.0 \\
\hline $31-40$ & 214 & 8.3 & 194 & 8.2 \\
\hline $41-50$ & 316 & 12.3 & 276 & 11.7 \\
\hline $51-60$ & 365 & 14.2 & 387 & 16.4 \\
\hline $61-70$ & 464 & 18.1 & 504 & 21.3 \\
\hline $71-80$ & 513 & 20.0 & 519 & 22.0 \\
\hline $81-90$ & 405 & 15.8 & 287 & 12.1 \\
\hline$>90$ & 82 & 3.2 & 36 & 1.5 \\
\hline No response & 0 & 0.0 & 4 & 0.2 \\
\hline \multicolumn{5}{|l|}{ Gender } \\
\hline Male & 1223 & 47.6 & 1125 & 47.6 \\
\hline Female & 1345 & 52.4 & 1234 & 52.2 \\
\hline No response & 0 & 0.0 & 4 & 0.2 \\
\hline \multicolumn{5}{|l|}{ Source CT request } \\
\hline Accident and Emergency & 462 & 18.0 & 291 & 12.3 \\
\hline Anaesthetist & 16 & 0.6 & 16 & 0.7 \\
\hline Obstetrics/gynaecology & 32 & 1.2 & 28 & 1.2 \\
\hline Physician & 492 & 19.2 & 163 & 6.9 \\
\hline $\begin{array}{l}\text { Surgeon (general/colorectal } \\
\text { upper GI) }\end{array}$ & 1478 & 57.6 & 1822 & 77.1 \\
\hline Surgeon - other & 19 & 0.7 & 3 & 0.1 \\
\hline Urologist & 40 & 1.6 & 17 & 0.7 \\
\hline Vascular surgeon & 24 & 0.9 & 17 & 0.7 \\
\hline Other & 5 & 0.2 & 2 & 0.1 \\
\hline No response & 0 & 0.0 & 4 & 0.2 \\
\hline \multicolumn{5}{|c|}{ Nature of provisional CT reporter } \\
\hline Off-siter & 210 & 8.2 & 181 & 7.7 \\
\hline Registrar & 887 & 34.5 & 882 & 37.3 \\
\hline $\begin{array}{l}\text { Hospital consultant, } \\
\text { unspecified }\end{array}$ & 22 & 0.9 & 0 & 0.0 \\
\hline Hospital consultant, general & 1028 & 40.0 & 876 & 37.1 \\
\hline $\begin{array}{l}\text { Hospital consultant, GI } \\
\text { interest }\end{array}$ & 146 & 5.7 & 128 & 5.4 \\
\hline $\begin{array}{l}\text { Hospital consultant, GI } \\
\text { subspecialty interest (min } \\
5 \text { sessions) GI radiology }\end{array}$ & 275 & 10.7 & 259 & 11.0 \\
\hline No response & 0 & 0.0 & 37 & 1.6 \\
\hline \multicolumn{5}{|c|}{$\begin{array}{l}\text { Nature of on-site consultant radiologist addendum reporter } \\
\quad \text { (non-surgical, } n=621 \text {; surgical, } n=635 \text { ) }\end{array}$} \\
\hline General radiologist & 466 & 75.0 & 442 & 69.6 \\
\hline $\begin{array}{l}\text { General with GI interest } \\
\text { (attends GI MDT) }\end{array}$ & 27 & 4.3 & 28 & 4.4 \\
\hline $\begin{array}{l}\text { GI radiology subspecialty } \\
\text { interest ( } \min 5 \text { sessions } \\
\text { per week) }\end{array}$ & 112 & 18.0 & 144 & 22.7 \\
\hline No response & 16 & 2.6 & 21 & 3.3 \\
\hline
\end{tabular}

CT, computed tomography; GI, gastrointestinal; MDT, multidisciplinary team.

in Scotland 8.5\%; however, this was not statistically significant.

\section{Overview of CT report concordance}

A detailed overview of these data is included in Electronic Supplementary Material Appendix B.

\section{Non-surgical group}

In total, 1,947 patients had a provisional CT report with no evidence of addendum and of these there was concordance with the auditor in 1,782 patients; 621 patients had evidence of an addendum report with provisional, addendum, and auditor reports concordant in 472 patients. Varying levels of discordance were noted in the remaining patients (Electronic Supplementary Material Appendix B) with the most prominent category being auditor concordance with addendum and not with provisional (75 patients).

\section{Surgical group}

In total, 1,728 patients had a provisional CT report with no evidence of an addendum and of these the provisional report was concordant with the auditor in 1,557 patients. In $1,423 / 1,557$ there was also agreement with laparotomy. Six hundred and thirty-five patients had evidence of an addendum report with provisional, addendum, and auditor reports concordant in 510 of these patients. Varying levels of discordance were noted in the remaining patients (Electronic Supplementary Material Appendix B) with again the most prominent category being auditor concordance with addendum and not with provisional (72 patients). In the 510 patients with concordance in all three reports, there was also agreement with laparotomy findings in 471 (39 disagreed).

\section{Nature of discrepancies and patient harm}

Summary characteristics and analysis by type of major discrepancies are included in Table 4 . The number of additional incorrect secondary major diagnoses was greater in provisional (six non-surgical, 10 surgical) than addendum reports (one in each group). There were single incidents of additional indeterminate reporting in non-surgical provisional and addendum reports and in surgical provisional reports.

\section{Non-surgical group}

In 47 patients, there was evidence on notes/imaging review of subsequent additional procedures that may have been unnecessary following a major discrepancy. These were predominantly additional imaging procedures, but also included CT/ultrasound guided drainage (three patients), laparoscopy (three patients), and endoscopy (three patients). Fifteen of 72 patients with provisional report major discrepancy were considered by the auditor to have come to harm as a result of the report: delay in diagnosis (seven patients), delay in treatment (seven patients), unnecessary investigations (two patients), and unspecified (one patient).

\section{Surgical group}

Thirty-six of the 132 patients with provisional report major discrepancy were considered by the auditor to have come to harm as a result of the report and were detailed as follows: delay in diagnosis (three patients), delay in surgery 
Table 4

Characteristics of major discrepancies on computed tomography (CT) auditor review.

\begin{tabular}{|c|c|c|c|c|c|c|c|c|}
\hline & \multicolumn{4}{|c|}{ Non-surgical } & \multicolumn{4}{|c|}{ Surgical } \\
\hline & \multicolumn{2}{|c|}{$\begin{array}{l}\text { Provisional } \\
(n=72)\end{array}$} & \multicolumn{2}{|c|}{$\begin{array}{l}\text { Addendum } \\
(n=19)\end{array}$} & \multicolumn{2}{|c|}{$\begin{array}{l}\text { Provisional } \\
(n=132)\end{array}$} & \multicolumn{2}{|c|}{$\begin{array}{l}\text { Addendum } \\
(n=17)\end{array}$} \\
\hline & $n$ & $\%$ & $N$ & $\%$ & $N$ & $\%$ & $n$ & $\%$ \\
\hline \multicolumn{9}{|c|}{ Nature of the discrepancy } \\
\hline False negative & 25 & 34.7 & 9 & 47.4 & 40 & 30.3 & 4 & 23.5 \\
\hline False positive & 13 & 18.1 & 3 & 15.8 & 8 & 6.1 & 1 & 5.9 \\
\hline $\begin{array}{l}\text { Indeterminate } \\
\text { reporting }\end{array}$ & 4 & 5.6 & 0 & 0.0 & 16 & 12.1 & 2 & 11.8 \\
\hline Misdiagnosis & 24 & 33.3 & 5 & 26.3 & 50 & 37.9 & 8 & 47.1 \\
\hline No response & 6 & 8.3 & 2 & 10.5 & 18 & 13.6 & 2 & 11.8 \\
\hline
\end{tabular}

(24 patients), unnecessary investigations (one patient), and unnecessary surgery (eight patients).

\section{Results of statistical analyses}

The full results of all analyses are included in Electronic Supplementary Material Appendix C.

\section{Predictors of provisional agreement with auditor (pooled} non-surgical and surgical data)

Table 5 shows risks of major discrepancy for on-site consultants, radiology registrars, and off-site reporters separately in the surgical and non-surgical groups. Overall risks of major discrepancy were $5.6 \%$ in the surgical group and $2.8 \%$ in the non-surgical group. In each group, major discrepancy risks were highest in off-site reporters and lowest in on-site consultants, although these between group differences only achieved statistical significance in the surgical group ( $p=0.0003$ ). There was no evidence that the major discrepancy risk ratios differed between the two groups ( $p=0.36)$ suggesting results could be pooled. In the combined analysis, major discrepancy risks were $44 \%$ higher (95\% confidence interval [CI]: $5 \%$ lower to $118 \%$ higher) in registrars than on-site consultants and $181 \%$ higher (95\% CI: 75\% to 351\% higher) in off-site reports than registrars ( $p=0.0001$, joint test of differences). Restricting to major discrepancies where the patient came to harm numbers were reduced but the pattern of results was similar (sections 1.1.5 to 1.1.7 in Electronic Supplementary Material Appendix C); for the pooled analysis the joint test of differences among the three groups was borderline statistically significant $(p=0.061)$ with risks statistically significantly higher for the off-site group compared to the on-site consultants $(p=0.018)$. A similar pattern of discrepancy risk ratios was seen when all discrepancies, not just major discrepancies, were considered (sections 1.1.4 in Electronic Supplementary Material Appendix C).

There was little evidence of differences in risks of discrepancy according to whether or not registrars discussed their interpretations with a consultant (section 1.2 Electronic Supplementary Material Appendix C). Among consultants, discrepancy risks were lower in those with a GI interest or a GI subspecialty than in those without such specialisation (section 1.3 Electronic Supplementary Material Appendix C). Combining the two specialist groups, risk of a major discrepancy was $28 \%$ lower (95\% CI: $57 \%$ lower to $21 \%$ higher) and risk of discrepancy was $32 \%$ lower (95\% CI: $5 \%$ to $51 \%$ ), with this latter difference achieving statistical significance $(p=0.022)$.

Regarding institutional comparisons, there was no evidence of differences in discrepancy risks between district general hospitals and teaching hospitals (section 1.4 Electronic Supplementary Material Appendix C). There was evidence that major discrepancy risk ratios were higher in hospitals where on-call registrar reporting was available (risks increased by $76 \%$ [95\% CI: $9 \%$ to $184 \%, p=0.021$ ] in the pooled analysis); however, this difference was much reduced in magnitude and became non-statistically significant when adjusted for registrar/on-site consultant/offsiter imbalances between institutions (section 1.5 Electronic Supplementary Material Appendix C).

There was also evidence that major discrepancy risk ratios were higher in hospitals where on-call CT reporting by on-site consultants was available (section 1.6 Electronic Supplementary Material Appendix C). In both the nonsurgical and surgical groups major discrepancy risks were lowest (2.3\% in the non-surgical group, $3.8 \%$ in the surgical group) when on-call CT reporting by an on-site consultant was fully available. When this was partially or not available risks were higher $(3.4 \%$ and $3.6 \%$ respectively in the nonsurgical group, $8 \%$ and $8.2 \%$ in the surgical group) although these between group differences only achieved statistical significance in the surgical group $(p=0.0093)$. There was no evidence that the major discrepancy risk ratios differed between the two groups $(p=0.56)$ suggesting results could be pooled. In the combined analysis major discrepancy risks were $85 \%$ (95\% CI: $20 \%$ to $188 \%$ ) higher

Table 5

Comparison of risks of major discrepancies between provisional report and auditor for consultants, registrars, and off-siters.

\begin{tabular}{|c|c|c|c|c|c|}
\hline \multirow[t]{2}{*}{ Group } & \multicolumn{2}{|c|}{ Non-surgical discrepancies } & \multicolumn{2}{|c|}{ Surgical discrepancies } & \multirow{2}{*}{$\begin{array}{l}\text { Pooled } \\
\text { Risk ratio } \\
(95 \% \text { CI }\end{array}$} \\
\hline & Numbers (\%) & $\begin{array}{l}\text { Risk ratio } \\
(95 \% \mathrm{CI})\end{array}$ & $\begin{array}{l}\text { Numbers } \\
\text { (\%) }\end{array}$ & $\begin{array}{l}\text { Risk ratio } \\
(95 \% \mathrm{CI})\end{array}$ & \\
\hline consultant & $36 / 1471(2.4 \%)$ & 1 & $49 / 1263(3.9 \%)$ & 1 & 1 \\
\hline Registrar & $25 / 887$ (2.8\%) & $1.15(0.65,2.03)$ & $56 / 882(6.3 \%)$ & $1.64(0.98,2.74)$ & $1.44(0.95,2.18)$ \\
\hline Off-siter & $11 / 210(5.2 \%)$ & $2.14(1.01,4.54)$ & $23 / 181(12.7 \%)$ & $3.28(1.84,5.84)$ & $2.81(1.75,4.51)$ \\
\hline No response & - & - & $4 / 37(10.8 \%)$ & - & - \\
\hline Total & $72 / 2568(2.8 \%)$ & - & $132 / 2363(5.6 \%)$ & - & - \\
\hline Between group comparison & - & $\mathrm{p}=0.12$ & - & $\mathrm{p}=0.0003$ & $\mathrm{p}=0.0001$ \\
\hline
\end{tabular}

CI, confidence interval. 
when on-call CT reporting was partially available and 90\% (95\% CI: $6 \%$ to $239 \%$ ) higher when this was not available compared to when it was fully available. These differences were somewhat reduced in magnitude when adjusted for registrar/on-site consultant/off-siter imbalances between institutions with the overall test of adjusted differences between groups being only borderline statistically significant $(p=0.066)$.

There was also evidence that discrepancy risks were higher when on call CT reporting was carried out by offrather than on-site radiologists (risks increased by $61 \%$ ( $95 \%$ CI: $6 \%$ to $145 \%, p=0.025$ ) in pooled analysis); however, this difference was again reduced in magnitude and became non-statistically significant when adjusted for registrar/onsite consultant/off-siter imbalances between institutions (section 1.7 Electronic Supplementary Material Appendix C). There was no evidence that the availability of a speciality GI radiologist on-site, or that routine on-site consultant review of outsourced CT on-call reports was associated with risks of discrepancy (sections 1.8 and 1.9 Electronic Supplementary Material Appendix C).

Table 6 shows where discrepancy occurred between addendum, provisional, and auditor reports in the subset of the data where an addendum report was available. There are five eventualities: all reports can agree, all can disagree, or any pair can agree whilst disagreeing with the third. The net benefit of the addendum can be assessed by comparing the number of occasions when the auditor agrees with the addendum but not the provisional with the number of occasions where the auditor agrees with provisional but not the addendum. In the non-surgical group, there was net benefit from switching to an addendum report in terms of major discrepancies (19 resolved, three introduced) and in terms of all discrepancies (75 resolved, 26 introduced). Using conditional logistic regression both differences were statistically significant $(p=0.006$ major discrepancy, $p<0.0001$ all discrepancies).

In the surgical group, there was also a strong net benefit in switching to an addendum, both in terms of major discrepancies (45 resolved, two introduced) and all discrepancies (72 resolved, 13 introduced). Using conditional logistic regression both differences were statistically significant $(p<0001)$.

\section{Availability of results preoperatively}

A written or validated RIS provisional report was available preoperatively in $98.3 \%$ of patients (Table 1 ). A written or validated addendum report was only available preoperatively in $64.3 \%$ of patients. In 45 patients with a major discrepancy at provisional report level, the discrepancy was corrected at addendum. In 14/45 of these cases, the addendum was not available preoperatively; hence, there were 14 cases of potentially avoidable major discrepancy (only $1 / 14$ patients came to harm).

\section{"Normal" CT and laparotomy findings}

Twenty-two patients had a "normal" laparotomy. Of these, 10 patients also had a "normal" provisional CT report with pathology reported in 12 patients (including cases of ischaemia, Crohn's disease, appendicitis, colitis). Twentythree patients had a "normal" CT report and still proceeded to laparotomy. Of these patients, 10 also had a normal laparotomy with pathology found in the remaining 13 including three cases of appendicitis, three cases of ischaemic bowel, one abscess, and two small bowel obstructions, "no response" in four patients).

\section{Overall compliance with audit standards}

These are documented in Table 1. Overall registrars met the audit standard for correlation of provisional report with laparotomy (standard $>80 \%$, achieved $83.7 \%$ ), but on-site consultants narrowly missed their standard (standard $>90 \%$, achieved $87.2 \%$ ). Off-site radiologists missed their target by a larger margin (standard $>90 \%$, achieved $78.9 \%$ ).

Table 6

Discrepancies between auditor and either provisional, addendum or both, for reports with an addendum.

\begin{tabular}{|c|c|c|c|c|c|c|c|}
\hline & \multirow{2}{*}{$\begin{array}{l}\text { No discrepancy } \\
\text { with either } \\
\text { provisional or } \\
\text { addendum }\end{array}$} & \multirow{2}{*}{$\begin{array}{l}\text { Discrepancy } \\
\text { with provisional, } \\
\text { but not with } \\
\text { addendum }\end{array}$} & \multirow{2}{*}{$\begin{array}{l}\text { Discrepancy } \\
\text { with addendum, } \\
\text { not with } \\
\text { provisional }\end{array}$} & \multicolumn{3}{|c|}{ Discrepancy with both provisional and addendum } & \multirow{2}{*}{$\begin{array}{l}\text { Overall risk of } \\
\text { discrepancy }\end{array}$} \\
\hline & & & & $\begin{array}{l}\text { Provisional and } \\
\text { addendum agree }\end{array}$ & $\begin{array}{l}\text { Provisional and } \\
\text { addendum } \\
\text { disagree }\end{array}$ & Provisional & \\
\hline \multicolumn{8}{|l|}{ All discrepancies: } \\
\hline Non-Surgical $(n=621)$ & 472 & 75 & 26 & 35 & 13 & $\begin{array}{l}75+35+13=123 / \\
621(19.8 \%)\end{array}$ & $\begin{array}{l}26+35+13=74 / 621 \\
(11.9 \%) \\
p<0.0001\end{array}$ \\
\hline \multicolumn{8}{|l|}{ Major discrepancies only: } \\
\hline Non-Surgical $(n=621)$ & 583 & 19 & 3 & 12 & 4 & $\begin{array}{l}19+12+4=35 / 621 \\
(5.6 \%)\end{array}$ & $\begin{array}{l}3+12+4=19 / 621 \\
(3.1 \%) \\
p=0.006\end{array}$ \\
\hline $\begin{array}{l}\text { Surgical } \\
\qquad(n=635)\end{array}$ & 573 & 45 & 2 & 8 & 7 & $\begin{array}{l}45+8+7=60 / 635 \\
(9.4 \%)\end{array}$ & $\begin{array}{l}2+8+7=17 / 635 \\
(2.7 \%) \\
p<0.0001\end{array}$ \\
\hline
\end{tabular}


Sensitivity/specificity data for the common pathologies

For results of these calculations please see Electronic Supplementary Material Appendix D.

\section{Discussion}

Discrepancy in radiological reporting is a complex issue and the causes of discrepancy are numerous, well recognised and often inter-related. ${ }^{5,6}$ Radiologist specific causes include faulty reasoning, lack of knowledge (particularly when working outside an individual's area of specialty expertise), failure of perception, or poor communication of findings. System-related factors are also important and a number of causes are recognised: staff shortages (with over reliance on locum radiologists), combined with excess workload, inexperience of staff, and insufficient or inaccurate clinical and/or previous radiological information. ${ }^{5}$

The investigation of discrepancy rates and related causes in radiology has been the subject of numerous publications with an emphasis on radiology registrar reporting, trauma, and cranial CT. ${ }^{21-25}$ There is variation in published rates for discrepancy in CT abdominal reporting and again these papers predominantly assess registrar reporting and there are differences in sample sizes and also definitions of discrepancy. Allowing for this discrepancy rates for CT abdomen reporting range widely from $<0.1 \%$ to 18\%. $8,12,14,17,26-31$ A meta-analysis looking at discrepancy rates in adult CT (all types and including elective and emergency) demonstrated overall no significant differences in rates of discrepancy between a registrar and more senior radiologists, with a pooled discrepancy rate for abdominopelvic CT of $2.6 \%{ }^{32}$ A recent study looking at abdominal CT in surgical patients found a $14 \%$ rate (146/1071 reports) of clinically important management changes following double/expert reading of initial CT reports. ${ }^{33}$ There is a relative paucity of published literature pertaining to discrepancy in outsourced, off-site radiology, a large series published in 2005 looking at a radiological group practice, reported a discrepancy rate of $2.1 \%$ for CT of the abdomen/ pelvis. ${ }^{20}$

The demand for access to radiology services continues to increase year on year in the UK. Due to its high diagnostic accuracy and increased availability CT has experienced a rapid expansion in its roles both in and out of hours; a growth of $141 \%$ in CT examinations was reported in the USA over a 10 year period. ${ }^{34}$ Unfortunately, the increased diagnostic imaging workload has not been matched by an increase in reporting radiologists. This is a situation that is particularly acute in the UK, but is also recognised worldwide. It is challenging to maintain a 24-hour service, 7-days a week and to ensure that emergency imaging, in particular $\mathrm{CT}$, is reported in a timely and accurate manner. These service challenges have led to the development of other reporting models: registrars often provide the first tier of reporting; however, increasingly hospitals have been looking at off-site/outsourced radiology reporting solutions, particularly during antisocial hours and weekends.
Outsourcing is now widely used in the UK, but it is a worldwide phenomenon with remote reporting hubs in India, Australasia, Europe, and the USA. ${ }^{35,36}$

The present study incorporated 4,931 patients from 108 UK radiology departments. It explored in detail factors that might be related to increased major discrepancy at the level of the provisional (initial) radiology report on review by a CT auditor. When compared to an on-site consultant there was a statistically significant increased risk of major discrepancy and major discrepancy with harm in an off-site/ outsourced CT report, this finding was consistent in both surgical and pooled data. Major discrepancy was also found to be more likely in the surgical group; registrars had a major discrepancy rate intermediate between on-site consultants and off-site reporting radiologists. These findings are also reflected in failure of compliance with the major discrepancy audit standards. Off-site reporters narrowly missed the non-surgical major discrepancy standard (standard $<5 \%$, achieved $5.2 \%$ ), but also missed the surgical major discrepancy (standard $<5 \%$, achieved $12.7 \%$ ) and pooled (standard $<5 \%$, achieved $8.7 \%$ ) standards. Both registrars and on-site consultants were able to meet the recommended provisional report standards for major discrepancy. The overall major discrepancy rate (patient came to harm) standard was also missed in the surgical group (standard $<1 \%$, achieved $1.5 \%$ ).

These results do raise important questions and there are no immediate or straightforward solutions. It is clear in the UK at least that the national shortage of consultant radiologists is going to persist with no short- or medium-term answers to the workforce shortfall. Hence the off-site and outsourced solution is not only attractive but has become a necessity in many hospitals. The issue of concern is maintaining quality in the outsourced arena. Many of the reported factors associated with increased risk of discrepancy are particularly relevant to a remote, off-site reporter. ${ }^{5}$ Factors particularly affecting off-site reporters include: excess workload, fatigue, exposure to a wide range of studies for reporting not reflecting their specialty training and experience, lack of clinical contact and clinical information, lack of access to previous imaging, and problems with communication. There is no doubt that the presence of local clinical networks, where radiologists work closely with surgical teams, can enhance the quality of CT reporting. Lack of access to these established networks is a significant disadvantage to radiologists reporting remotely. ${ }^{37}$ Close in-person collaboration between the reporting radiologist and the surgical team is associated with significant and also frequent changes in patient management, even when the radiological report is correct and contains the necessary diagnostic information. ${ }^{38}$ There is another important potential side-effect of increased utilisation of outsourced reporting, namely reduced exposure of radiology trainees to on-call experience. When managed appropriately involvement in out-of-hours, emergency radiology is an invaluable part of radiology training. Reducing this exposure, outsourcing is one important cause of this, is likely to have a significant and deleterious effect on training the radiologists of the future. ${ }^{39}$ 
The audit also evaluated the addendum/supplementary report and availability of reports in surgical patients preoperatively. This was partly in response to the recently published UK National Emergency Laparotomy Audit, ${ }^{40}$ which highlighted deficiencies in consultant radiologist reported abdominopelvic CT prior to surgery (53\%). This laparotomy audit did acknowledge that 24-hour contemporaneous reporting was available at all hospitals in the audit offering laparotomy, though the grade of reporting radiologist was not specified.

In the present study, a written/validated RIS provisional report was available pre-laparotomy in $98.3 \%$ of patients (standard $100 \%$ ), but only $64.3 \%$ of addendum reports were available preoperatively (standard $100 \%$ ). Of note, the majority of departments in the audit offered secondary review of registrar provisional reports with the issuing of an addendum, usually by the rostered CT consultant radiologist the next morning. The majority (22/38) of departments utilising off-site CT reporters do not routinely review offsite on call CT reports.

The study did establish the value of the on-site consultant addendum report with statistically significant benefits of switching to an addendum in terms of reducing both major and all discrepancies within provisional reports and in both non-surgical and more markedly the surgical groups. The timing of issue of addendum reports is also relevant (see earlier) for them to have appropriate clinical impact. A benefit in terms of reduction in major discrepancy in provisional reporting was also noted in the audit when evaluating the availability of a specialist GI radiologist. Clearly numbers of specialist GI radiologists are relatively limited but there may be a role for both addendum double reading and peer review by GI radiologists of abdominopelvic CT on-call where resources allow.

This study does have limitations. It was performed retrospectively and as such findings do rely on availability and accuracy of relevant documentation. The results reflect practice from 2013. Data were incomplete in some sections and also the prevalence of discussion of cases by registrars with on-site consultants may not be fully reflected in the reports, possibly enhancing the accuracy of registrar reporting. The response rate overall of $58 \%$ bears favourable comparison other similar published studies in the literature. ${ }^{7,41}$ There was no evidence of significant response bias: only small percentage differences were evident between proportions of departments from teaching and nonteaching hospitals who did and did not respond, similar findings were found when looking at geographical response rates.

In conclusion, this study provides data on factors influencing discrepancy rate in the provisional (initial) radiological report in a large cohort of patients undergoing emergency abdominal CT. The lowest rate of discrepancy was found when reporting was undertaken by on-site consultant radiologists. Statistically significant increases in the rates of major discrepancy and in patients coming to harm were found when reporting was undertaken by a radiologist at a site remote from the image acquisition. Patients undergoing surgery were at a greater risk of major discrepancy and harm than non-surgical patients. These findings give cause for concern and should provide impetus for further consideration of optimal models of service provision for the reporting of emergency abdominal CT. It is clear that both the seniority and location of the reporter can have a significant effect on the accuracy of emergency CT reporting and hence patient outcomes. Radiological departments should also ensure that a robust and timely system of on-site consultant addendum reporting is in place as a safety net for registrar and off-site reporters.

\section{Appendix A. Supplementary data}

Supplementary data related to this article can be found at http://dx.doi.org/10.1016/j.crad.2016.10.008.

\section{References}

1. Brewer BJ, Golden GT, Hitch DC, et al. Abdominal pain: an analysis of 1000 consecutive cases in a University Hospital setting. Am J Surg 1976;131:219-23. http://www.americanjournalofsurgery.com/article/ 0002-9610(76)90101-X/abstract.

2. Sala E, Watson CJ, Beardsmoore C. A randomised controlled trial of routine early abdominal CT in patients presenting with non-specific acute abdominal pain. Clin Radiol 2007;62:961-9.

3. Tsushima Y, Yamada S, Aoki J. Effect of contrast enhanced CT on the diagnosis and management of the acute abdomen in adults. Clin Radiol 2002;57:507-13.

4. Rosen MP, Sands D, Longmaid H. Impact of abdominal CT on the management of patients presenting in the emergency department with acute abdominal pain. AJR Am J Roentgenol 2000;174:1391-6.

5. Brady A, Olaoide R, McCarthy P, et al. Discrepancy and error in radiology: concepts, causes and consequences. Ulster Med J 2012;81(1):3-9.

6. Goddard P, Leslie A, Jones A, et al. Error in Radiology. Br J Radiol 2001;74:949-51.

7. Howlett D, Drinkwater K, Lawrence D, et al. Findings of a UK national audit evaluating image guided and image assisted liver biopsy. Part 1 Procedural aspects, diagnostic adequacy and accuracy. Radiology 2012;265(3):821-2. http://pubs.rsna.org/doi/10.1148/radiol.12120224.

8. Weir-McCall J, Shaw A, Knight A, et al. The use of preoperative CT in the assessment of the acute abdomen. Ann $R$ Coll Surg Eng 2012;94(2):102-7.

9. Briggs RH, Rowbotham E, Johnstone AL, et al. Provisional reporting of polytrauma CT by on-call radiology registrars: is it safe? Clin Radiol 2010;65:616-22.

10. Agostin C, Durieux M, Milot L. Value of double reading of whole body CT in poly trauma patients. J Radiol 2008;89:325-30. https://www.ncbi. nlm.nih.gov/pubmed/18408631.

11. Hillier JC, Tattersall DJ, Gleeson FV. Trainee reporting of CT examinations, do they make mistakes and does it matter? Clin Radiol 2004;59:159-62.

12. Tieng N, Grinberg F, Li SF. Discrepancies in interpretation of ED Body CT scans by radiology residents. Am J Emerg Med 2007;25(2):45-8.

13. Chung JH, Strigel RM, Chew AR, et al. Overnight resident interpretation of torso CT at a level 1 trauma centre: an analysis and review of the literature. Acad Radiol 2009;16(9):1155-60.

14. Kang MJ, Sim MS, Shin TG, et al. Evaluating the accuracy of emergency medicine resident interpretations of abdominal CTs in patients with non-traumatic abdominal pain. J Korean Med Sci 2012;27(10):1255-60.

15. Carney E, Kempf J, DeCarvalho V, et al. Preliminary interpretations of after-hours CT and sonography by radiology residents versus final interpretations by body imaging radiologists at a level 1 trauma centre. AJR Am J Roentgenol 2003;181:367-73.

16. Cooper VF, Goodhartz LA, Nemcek AA, et al. Radiology resident interpretations of on-call imaging studies: the incidence of major discrepancies. Acad Radiol 2008;15:1198-204. 
17. Walls J, Hunter N, Brasher PM, et al. The DePICTORS study: discrepancies in preliminary interpretation of CT scans between on-call residents and staff. Emerg Radiol 2009;16:303-8.

18. Ruutiainen AT, Scanlon MH, Itri JN. Identifying benchmarks for discrepancy rates in preliminary interpretations provided by radiology trainees at an academic institution. J Am Coll Radiol 2011;8(9):644-8.

19. Ruchman RB, Jaeger J, Wiggins EF, et al. Preliminary radiology resident interpretations versus final attending radiologist interpretations and the impact on patient care in a community hospital. AJR Am J Roentgenol 2007; 189(3):523-6.

20. Wong WS, Roubal I, Jackson DB, et al. Outsourced teleradiology imaging services: on analysis of discordant interpretation in 124, 870 cases. J Am Coll Radiol 2005;2(9):804-9. http://www.sciencedirect.com/science article/pii/S1546144004004661.

21. Yaniv G, Mozes O, Greenberg G, et al. Common sites and aetiologies of resident's misinterpretation of head CT scans in the emergency department of a level 1 trauma centre. Isr Med Assoc J 2013;15(5): $221-5$.

22. Miyakoshi A, Nguyen Q, Cohen W, et al. Accuracy of preliminary interpretations of neurologic CT examinations by on-call radiology residents and assessment of patient outcomes at a level 1 trauma centre. $J$ Am Coll Radiol 2009;6(12):864-70.

23. Strub W, Leach J, Tomsick T, et al. Overnight preliminary head CT interpretations provided by residents: locations of misidentified intracranial haemorrhage. AJNR Am J Neuroradiol 2007;28(9):1679-82.

24. Roszler M, McCarroll K, Rashid T, et al. Resident interpretation of emergency CT scans. Invest Radiol 1991;26(4):374-6.

25. Wysoki M, Nassar C, Koenigsberg R, et al. Head trauma: CT scan interpretation by radiology residents versus staff radiologists. Radiology 1998;208(1):125-8.

26. De Witt J, Griffith-Richards S, Pitcher R. The accuracy of after hours registrar CT reporting in a South African tertiary teaching hospital. SA J Radiol 2014;18(1):3. http://dx.doi.org/10.4102/sajr.v18i1.591.

27. Ruma J, Klein K, Chong S, et al. Cross sectional examination interpretation discrepancies between on-call diagnostic radiology residents and subspecialty faculty radiologists: analysis by imaging modality and subspecialty. J Am Coll Radiol 2011;8(6):409-14.

28. Strub W, Vagal A, Tomsick T, et al. Overnight resident preliminary interpretations of CT examinations; should the process continue? Emerg Radiol 2006;13(1):19-23.
29. Lowe L, Draud K, Hernanz-Schulman M, et al. Non-enhanced limited CT in children suspected of having appendicitis: prospective comparison of attending and resident interpretations. Radiology 2001;221(3):755-9.

30. Friedman S, Merman E, Chopra A. Clinical impact of diagnostic imaging discrepancy by radiology trainees in an urban teaching hospital emergency department. Int J Emerg Med 2013;6:24-9.

31. Terreblanche O, Androikou S, Hlabangana L, et al. Should registrars be reporting after hours CT scans? A calculation of error rate and the influencing factors in South Africa. Acta Radiol 2012;53(1):61-8.

32. Wu MZ, Mcinnes MD, Macdonald DB, et al. CT in adults: systematic review and meta-analysis of interpretation and discrepancy rates. Radiology 2014;270:717-35.

33. Lauritzen PM, Andersen JG, Stokke MV. Radiologist initiated double reading of abdominal CT: retrospective analysis of the clinical importance of changes to radiology reports. BMJ Qual Saf 2016;0:1-9. http:// dx.doi.org/10.1136/bmjqs-2015-004536.

34. Levin D, Rao V, Parker L. Ownership or leasing of CT scanners by nonradiologist physicians: a rapidly growing trend that causes concern about self-referral. Am J Coll Radiol 2008;5:1206-9.

35. Burute N, Jankharia B. Teleradiology: the Indian perspective. Indian J Radiol 2008;19(1):16-8. http://www.ijri.org/article.asp?issn=0971-3026; year $=2009 ;$ volume $=19 ;$ issue $=1 ;$ spage $=16$; epage $=18$; aulast $=$ Burute.

36. Reinus W. American radiology and outsourcing. Radiology 2007;242:654-7.

37. Quint L, Quint D, Myles J. Frequency and spectrum of errors in final radiology reports generated with automatic speech recognition technology. J Am Coll Radiol 2009;6(4):282-3. http://www.sciencedirect. com/science/article/pii/S154614400800361X.

38. Dickerson EC, Alam HB, Brown RKJ, et al. In-person communication between radiologists and acute care surgeons leads to significant alterations in surgical decision making. J Am Coll Radiol 2016;13(8):943-9.

39. Little D, McCoubrie P. Learning whilst on-call: a vital part of radiology training? Clin Radiol 2016;71:921-4.

40. NELA Project Team. First patient report of the National Emergency Laparotomy Audit. London: Royal College of Anaesthetists; 2015. http://www. nela.org.uk/All-Patient-Reports\#pt.

41. Barter S, Jones K, Drinkwater K, et al. The UK nephrostomy audit: can a voluntary registry produce robust performance data. Clin Radiol 2008;63(8):888-94. http://www.sciencedirect.com/science/article/pii/ S0009926008000998. 